\title{
Three-Point Bending Behavior of Web-Core Steel Sandwich Panel
}

\author{
Xiaoxia Jiang ${ }^{1,2}$, Liang Zhu ${ }^{2}$, Shangcai Fei ${ }^{3}$, Shuai Zhang ${ }^{1, *}$, Chunsheng $\mathrm{Hu}^{1}$ and Guan Wang ${ }^{1}$ \\ ${ }^{1}$ School of Mechanical Engineering, NingxiaUniversity, Yinchuan, 750021, China \\ ${ }^{2}$ State Key Laboratory of Advanced Processing and Recycling of Non-ferrous Metals, Lanzhou University of Technology, \\ Lanzhou, 730050, China \\ ${ }^{3}$ School of Mechanical Engineering, Qinghai Higher Vocational \&Technical Institute, Haidong, 810799, China
}

\begin{abstract}
Static three-point bending test of Web-core steel sandwich panel was performed. The deformation and failure of the sandwich structure were investigated,together with the finite element simulations, which considered the weld width of the laser-welded T-joint. The results indicate that the initial yield load is $25 \mathrm{kN}$, and the maximum bending load is $54 \mathrm{kN}$. The deformation could be divided into three stages. The first stage is the elastic deformation when the load less than the yield load. The second stage is the plasticity deformation when the load is larger than the yield load but less than the maximum load. It is suggested that the higher stability and load-carrying capacity of the sandwich panel. The third stage is the failure process. The failure of the sandwich panel can be ascribed preliminarily to the local bucking on the face plate under a large bending load. However, the FEM result suggested the failure mode is the $T$ joint failure, because the plasticity rings were formed before the bucking of the face plate. The laser welded $T$-joint is so important that the structural design shouldn't unnoticed the weld geometrical features.
\end{abstract}

Keywords-sandwich panel; three-point bending test; deformation; $T$-joint; failure

\section{INTRODUCTION}

Steel Sandwich panel consists of two face plates connected by the core plates result in high strength and stiffness, which lead promising design advantages. Steel sandwich panels are interesting of conceivable use in ships, building, and bridge structures especially in extreme environments, accidental or terrorist blasts [1,2].The contemporary interest in steel sandwich panels has been awakened by the developments in laser welding technology which enables the efficient production of these plates. Elevated pre-fabrication accuracy of the components, high welding speed and the possibility to connect internal stiffeners with the face plates from outside has led to a wide application of laser welding in the construction of steel sandwich panels [3].

Web-core steel sandwich panel has the simplest core structure, as showed in Figure 1 It has been under active investigations during the last 15 years. Romanoff studied the bending response of web-core sandwich panel using analytical and FEM methods, and the stiffness and strength analytical formulation of web-core sandwich were exposed [4,5]. Romanoff made a greater contribution to the shear stiffness of the web-core sandwich panel by bringing in the rotation stiffness of the T-joints.
A lot works about sandwich panel buckling strength has been done through analytical methods, finite element methods and experiments [6-8]. In these studies, the bending response is evaluated by transforming an originally discrete structure into an equivalent homogenous continuum giving a sandwich panel, or the T-joints of web-core sandwich panel was assumed as continuous features. Actually, the T-joint has a discontinuous features, i.e., there are root gap and inevitable weld offset, weld width is less than the thickness of the face or core plate. Ref. [9] reported the ultimate strength of corroded web-core steel sandwich beams both by the experiments and the finite element simulation research, and the weld width may reduce the strength of the panels. The deformation and failure of sandwich structure with different thicknesses of panel and foam core were investigated in Ref. [10].

This paper presents a typical three-point bending test on web-core steel sandwich panelto analyze the static mechanics and deformation. In order to realize and accentuate the importance of the laser-welded T-joint, the finite element method was performed to analyze the the deformation of the sandwich panel. The average weld width of the T-joints was considered in the finite element model. The process of deformation and the failure mode was mainly studied.

\section{EXPERIMENTAL}

\section{A. Sandwichpanel}

The web-core sandwich panel consists of web and face plates, which are connected by laser beam keyhole welding, as be shown in Figure 1 The welding power is $12 \mathrm{~kW}$. The welding speeding is $2000 \mathrm{~mm} / \mathrm{min}$. The shielding gas is Argon, and the gas flow is $30 \mathrm{~L} / \mathrm{min}$.

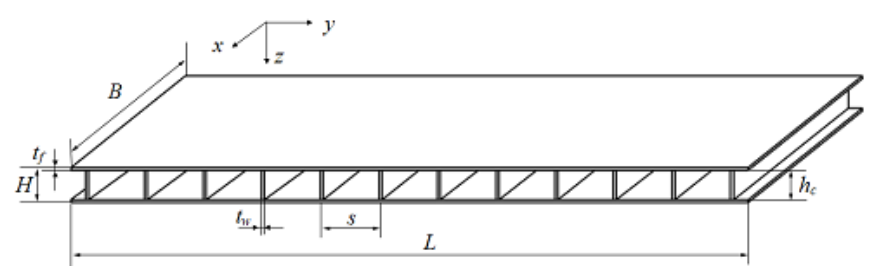

FIGURE I. THE DIMENSIONS OF SAMPLE PANEL

The base metal used in this paper is low alloy and high strength hull steel CCS-B. The yield strength of the base material is $298 \mathrm{MPa}$, and the tensile strength is $470 \mathrm{MPa}$.The main chemical composition shows in Table 1 . 
TABLE I. MAIN CHEMICAL COMPOSITION OF HULL-STEEL CCS-B

\begin{tabular}{|c|c|c|c|c|c|c|c|c|}
\hline \multicolumn{7}{|c|}{ Chemical Composition(\%) } \\
\hline $\mathrm{C}$ & $\mathrm{Mn}$ & $\mathrm{Si}$ & $\mathrm{P}$ & $\mathrm{S}$ & $\mathrm{Cu}$ & $\mathrm{Ni}$ & $\mathrm{Cr}$ & $\mathrm{Ti}$ \\
\hline 0.13 & 0.68 & 0.21 & 0.025 & 0.016 & 0.04 & 0.03 & 0.02 & $<0.0005$ \\
\hline
\end{tabular}

The thickness of the face and web plates are $4 \mathrm{~mm}$. The number of the core plate isn. The dimensions of optimized sandwich structures are listed in Table 2.

TABLE II. DIMENSIONS OF LASER WELDING SANDWICH PLANE STRUCTURE

\begin{tabular}{|c|c|c|c|c|c|c|}
\hline$L(\mathrm{~mm})$ & $B(\mathrm{~mm})$ & $H(\mathrm{~mm})$ & $h_{c}(\mathrm{~mm})$ & $t_{f}(\mathrm{~mm})$ & $t_{w}(\mathrm{~mm})$ & $n$ \\
\hline 1200 & 500 & 40 & 78 & 24 & 4 & 15 \\
\hline
\end{tabular}

\section{B. Equipment}

According to ASTM C393-00 standard test method for flexural properties of sandwich structures and GB/T 14562005Performance test methods for sandwich structures, a special test setup which is suitable for simply support, as be shown in Figure 2, was developed to measure the bending behaviors of sandwich panels. The static bending experiments were conducted on a $3150 \mathrm{kN}$ column hydraulic machine at the head speed is $5 \mathrm{~mm} / \mathrm{min}$, and the span is $936 \mathrm{~mm}$. The load and deflection were measured by the load and displacement sensor, respectively. And the whole deformation of the web-core sandwich panel was recorded by a high-performance camera with a micro-lens.

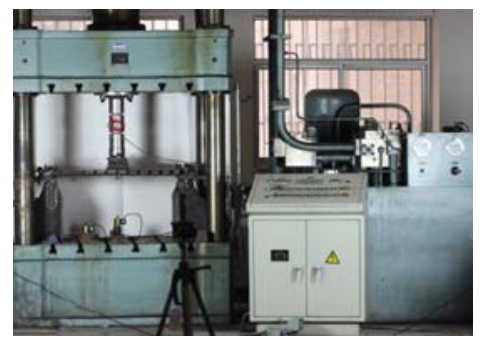

FIGURE II. THE SETUP AND TESTING MACHINE

\section{Finite Element Model}

The abaqus6.11 standard solver was employed to analyze bending behavior of the sandwich panel. The 2Dfinite element model considering the weld width (the average weld width $=1.8 \mathrm{~mm}$ ) was established, as shown in Figure 3, which also shown the meshing results. In this model, the weld locations are all in the middle of each core plate. The elements used are CPE8R. In general the aspect ratio in rectangular elements is kept close to $1: 2$ and the angle in quadrangular between $45^{\circ}-135^{\circ}$ to avoid problems in accuracy of solution. The material property of the hull steel had been measured by the tensile testing in Ref. [11].

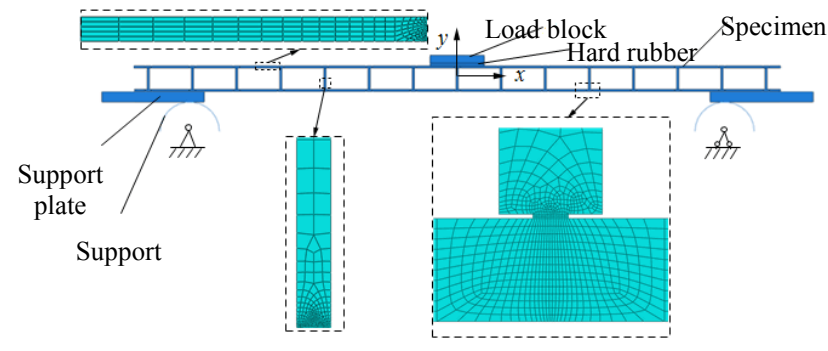

FIGURE III. FEM MODEL AND MESHIMG

\section{RESUlt AND DiCUSSION}

\section{A. Testing Result and Discussion}

Figure 4 shows the typical curves of deflection vs load of three-point bending tests, and the solid line is the test data. Figure V is the photographs of bending test, which represents bending process of sandwich structure at different time .As we can see, the load and deflection is linear relationship before the load smaller than $25 \mathrm{kN}$, which be called initial yield load. It means that the sandwich panel was in elastic deformation. As the increasing of the load, the relationship becomes nonlinear. It means that the sandwich panel was in plasticity deformation, which the load range is $25 \mathrm{kN}$ to the maximum load $54 \mathrm{KN}$. In this deformation stage, we divided it into two stages. Firstly, as the load increasing from $25 \mathrm{kN}$ to $45 \mathrm{kN}$, the deflection increased from $9 \mathrm{~mm}$ to $28 \mathrm{~mm}$. The larger increase of the load is corresponding to the smaller increase of the deflection. It is suggested that the higher ability to resist deformation of the sandwich panel. Secondly, as the load increasing from $45 \mathrm{kN}$ to $54 \mathrm{kN}$, the deflection increased from $28 \mathrm{~mm}$ to $91 \mathrm{~mm}$. The smaller increase of the load is corresponding to the larger increase of the deflection. It is indicated that the higher stability and load-carrying capacity of the sandwich panel. As the load over the maximum, obviously, it is found that the local buckling appeared on the face plate, see Figure 5 (c) and Figure 5 (d). As a result, the preliminary conclusion is that the failure type of the whole sandwich panel is the local bucking on the face plate.

In addition to, we are more interested in the deformation of the laser welded T-joints. The T-joint has some special characteristics, which could affect the whole deformation of the sandwich panel. Figure 6 shows the cross section characteristics of the laser welded T-joint. The weld width is less than the thickness of the core plate, and there is a root gap between face and core plate. The finite element method was conducted to analyze the deformation of the sandwich panel. The deflection vs load curve is shown in Figure 3, which is the dot dash line. As we can see, the agreement between calculated deflection and load and experimental results was found to be good. 


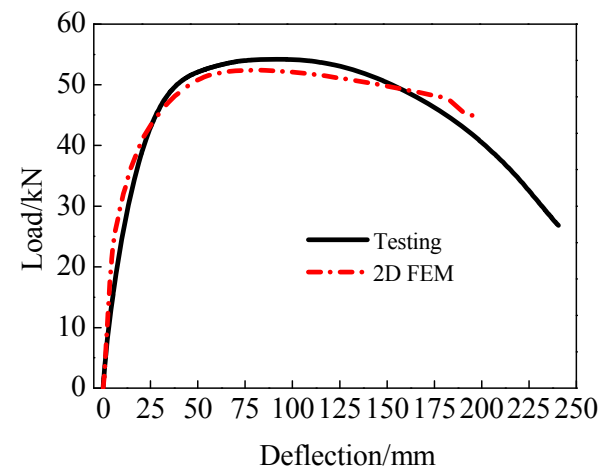

FIGURE IV. CURVES OF DEFLECTION VS LOAD OF SANDWICH PLATE DURING BENDING TEST

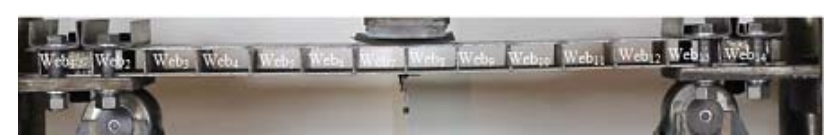

(a) Initial state $(\mathrm{Load}=0 \mathrm{kN}$, Deflection $=0 \mathrm{KN})$

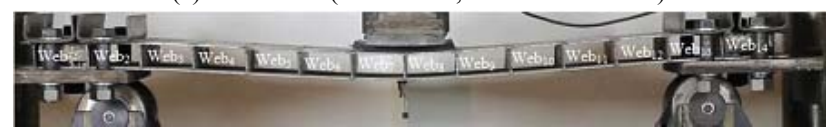

(b) Initial yeild $(\mathrm{Load}=25 \mathrm{kN}$, Deflection $=9.1 \mathrm{~mm})$

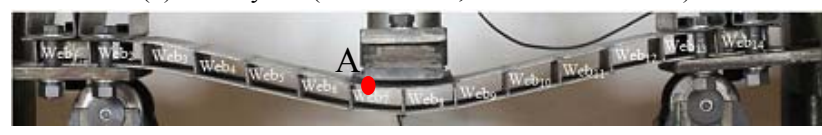

(c) Maximum loading $($ Load $=54.19 \mathrm{kN}$, Deflection $=91.2 \mathrm{~mm})$

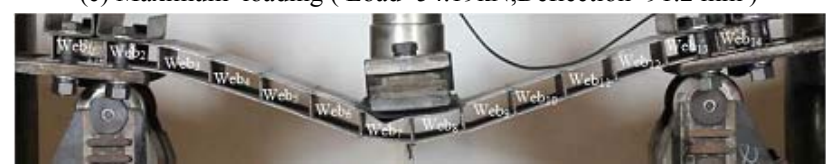

(d) Face plate buckling $(\operatorname{Load}=54.17 \mathrm{kN}$,Deflection=96.41 $\mathrm{mm})$

FIGURE V. PHOTOGRAPHS OF BENDING TEST OF SANDWICH PANEL:(a), (b), (c) AND (d) REPRESENT BENDING PROCESS OF SANDWICH STRUCTURE AT DIFFERENT TIME

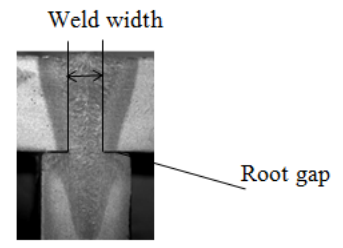

FIGURE VI. THE CROSS SECTION CHARACTERISTICS OF THE LASER WELDED T-JOINT

\section{B. FEM Result and Discussion}

Figure 7 displays the different stage deformation of the sandwich plate by the FEM. The red areas represent plasticity the strength is larger the material's yield strength. Based on the analysis, it is not difficult to make a summary that the main feature of deformation of sandwich plate is as follows:

(1) When the whole structure is in the elastic deformation, the yield of T-joint has developed. Figure 7 (b) is the typical process of the first plasticity ring formed. Actually, the yield point that the load and the deflection turn into nonlinear relationship not represents the yield of the face plate, but it represents the yield of the T-joint. As the increasing of the load, the other T-joints yield in proper sequence. Certainly, if there are a few welding defects, the poorestT-joint yield firstly.

(2) When the load reached the maximum value, the yield area along the thickness of face plate is larger than a half of the thickness face plate, as showed in Figure 7 (b), meanwhile the $\mathrm{T}$-joint close to the load center yield completely. In fact, the Tjoints showed cracking along the root gaps. As a result, the failure of the $\mathrm{T}$-joints and the failure of the face plates are carried out simultaneously. Which failure mode is the dominating position depends upon various factors, such as the structural parameters, welding parameters, the strength of material and so on. But it is at least indicated that some T-joints should be damaged before the face plates yielding in the cross section totally.

In a word, the laser welded T-joint play an important role in the deformation and failure of the Web-core sandwich panel, which will be determining the failure of the web-core steel sandwich panel by the mode with $\mathrm{T}$-joint formed the plasticity ring. The whole structure is losing stability before the load reached the maximum value because of the plasticity rings. Lastly, the damage mode for this type of web-core steel sandwich panel is the buckling of face plate, see Figure 7 (c).

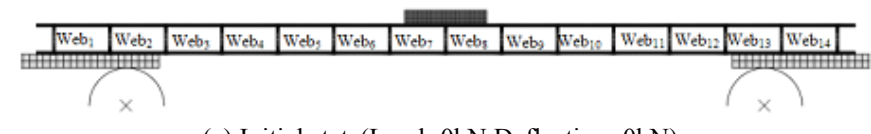

(a) Initial state $($ Load $=0 \mathrm{kN}$, Deflection $=0 \mathrm{kN})$

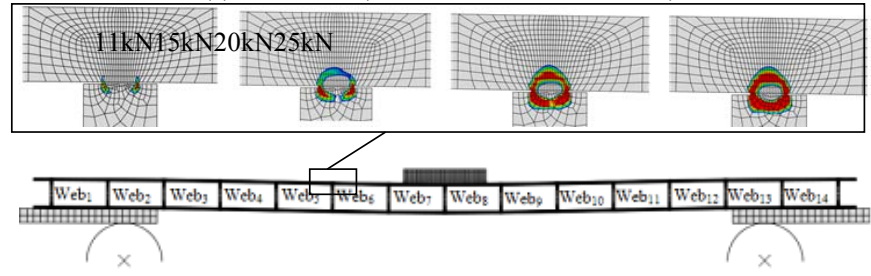

(b) Initial yeild $(\mathrm{Load}=25 \mathrm{kN}$,Deflection=9.1 mm)

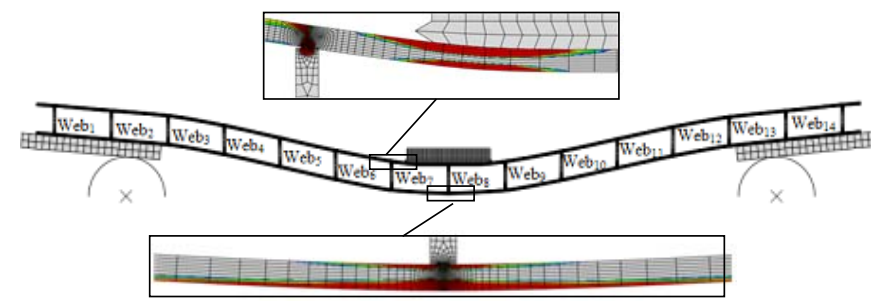

(c) Maximum loading ( Load=54.19kN,Deflection=91.2 mm )

FIGURE VII. FEM RESULTS FOR DEFORMATIONAND PLASTITY

EXTENSIONOFSANDWICH PANEL:(a), (b) AND (c)REPRESENT

BENDING PROCESS OF SANDWICH STRUCTURE AT DIFFERENT TIME

\section{CONCLUSION}

Base on the experimental investigation into the bending deformation of laser welded web-core sandwich panel, together with the finite element method to simulate three-point bending testing, the following conclusions can be drawn:

(1) The deformation process of the web-core steel sandwich panel is divided into three stages: the elastic deformation, plasticity deformation and failure process. The yield load is 25 
$\mathrm{kN}$. And the maximum load is $54 \mathrm{kN}$. The Web-core steel sandwich panel has higher stability and load-carrying capacity to withstand deformation and damage.

(2)In the plasticity deformation stage, it exhibits two fractal characteristics. One is that the load markedly increased didn't bring the deflection increased by a wide margin. The other is that the minor load increased made the displacement increased significantly.

(3) The T-joint formed plasticity ring before the face plate yield. Lastly, the failure mode is the yield of the T-joints, and the damage mode is the local buckling of the face plate. Therefore, it is very necessary to consider the weld geometrical features in the structural design.

\section{ACKNOWLEDGMENT}

This research work was funded by the National Nature Science Foundation of China (No. 51035004). This work is also supported by the Talent introduction of scientific research start-up fund project of Ningxia University (No. BQD2014021). The authors wish to thank the editors and reviewers for their comments and suggestions.

\section{REFERENCES}

[1] P. Kujala, A. Klanac, Steel Sandwich Panels in Marine Applications. Brodo Gradnja, 2005,56(4): 305-314.

[2] X. X.Jiang, L. Zhu , J. S. Qiao, Y.X. Wu, Z.G. Li.The Strength of Laser Welded Web-core Steel Sandwich Plates, Applied Mechanics and Materials, 2014, 551:42-46.

[3] J. Kozak. Selected problems on application of steel sandwich plates to marine structures.Polish Maritime Research, 2009,16(4):9-15.

[4] J. Romanoff, P. Kujala. Formulation For The Strength Analysis Of All Steel SandwichPlates.2002, M-266, Helsinki University of Technology Ship laboratory.

[5] J. Romanoff. Bending Response of Laser-Welded Web-core Sandwich Plates, HelsinkiUniversity of Technology. Doctoral Dissertation, 2007.

[6] H. Kolsters, D. Zenkert, Buckling of laser-welded sandwich panels. Part 1: Elastic bucklingparallel to the webs. Proceedings of the Institution of Mechanical Engineers, Part M: Journal ofEngineering for the Maritime, 2006, 220(2): 67-79.

[7] H. Kolsters, D. Zenkert, Buckling of laser-welded sandwich panels. Part 2: elastic bucklingnormal to the webs. Proceedings of the Institution of Mechanical Engineers, Part M: Journal ofEngineering for the Maritime Environment, 2006, 220(2): 81-94.

[8] H. Kolsters, D. Zenkert, Buckling of laser-welded sandwich panels: Ultimate strength andexperiments. Proceedings of the Institution of Mechanical Engineers, Part M: Journal ofEngineering for the Maritime Environment, 2010 , 224(1): 29-41.

[9] J. Jelovica, J. Romanoff, S. Ehlers, et al, Ultimate strength of corroded web-core sandwichbeams. Marine Structures, 2013, 31(2013): 1-14.

[10] G. Y. Zu, R. H. Lu, X. B. Li, Zh. Y. Zhong, Xing-jiang MA, Ming-bo HAN, Guang-chun YAO.Three-point bending behavior of aluminum foam sandwich with steel panel. Trans. Nonferrous Met. Soc. China 23(2013) 2491-2495

[11] X. X.Jiang, J. M.Li, R.Cao, L.Zhu, JH.Chen, Y.X.Wu, Z.G.Li, Microstructures and properties of sandwich plane laser-welded joint of hull steel, Materials Science and Engineering: A, 2014, 595: 43-53. 